\title{
Nowe dane do rozmieszczenia chronionych, zagrożonych i rzadkich mchów w Beskidzie Sądeckim (Karpaty Zachodnie)
}

\author{
AdAm Stebel i GRZEGorz VonČInA
}

\begin{abstract}
Stebel, A. And Vončina, G. 2020. New data on the distribution of protected, threatened and rare mosses in the Beskid Sądecki Mts (Poland, Western Carpathians). Fragmenta Floristica et Geobotanica Polonica 27(2): 253-267. e-ISSN 2449-8890, ISSN 1640-629X.

ABSTRACT: The paper contains information about 99 species and one variety of mosses from the Beskid Sądecki range, of which 36 species (e.g. Anomodon attenuatus, Neckera pennata, Zygodon rupestris) are protected by law and 10 (e.g. Neckera besseri, Syntrichia virescens, Tomentypnum nitens) are threatened in Poland. Eleven species (Aloina rigida, Bryum rubens, Cirriphyllum crassinervium, Eucladium verticillatum, Fissidens rufulus, Guembelia longirostris, Schistidium lancifolium, Schistidium papillosum, Sphagnum russowii, Thamnobryum neckeroides, Tortula modica) are first records for this region.
\end{abstract}

KEY WORDS: biodiversity, bryophytes, red-list species

A. Stebel, Katedra i Zakład Botaniki Farmaceutycznej i Zielarstwa, Wydział Nauk Farmaceutycznych, Ślqski Uniwersytet Medyczny w Katowicach, ul. Ostrogórska 30, 41-200 Sosnowiec, Polska; e-mail: astebel@sum.edu.pl

G. Vončina, Pieniński Park Narodowy, ul. Jagiellońska 107B, 34-450 Krościenko nad Dunajcem, Polska; e-mail: gvoncina@poczta.onet.pl

\section{WSTĘP}

Beskid Sądecki zajmuje około $670 \mathrm{~km}^{2}$ i stanowi wschodni kraniec Beskidów Zachodnich (Ryc. 1). Najwyższym szczytem pasma jest Radziejowa (1266 m n.p.m.).

Beskid Sądecki należy do regionów o dobrze poznanej florze mchów. Pierwsze informacje briologiczne z omawianego terenu pochodzą z drugiej połowy XIX w. (REHMAN 1869; KRUPA 1882, 1885). W 1977 r. ukazała się monografia flory mszaków Beskidu Sądeckiego (MAMCZARZ 1977). Od tego czasu opublikowano kilka kolejnych prac briologicznych, które przyniosły nowe dane do flory mchów tego obszaru (BRYLSKA 1991; OCHYRA i in. 1992, 2008, 2011; BednareK-Ochyra 1995; CyKowska 2008; BednAREK-OChyra i in. 2011; Stebel \& Vončina 2011; Stebel i in. 2011, 2018; PacioreK 2012; VonČInA w: Górski i in. 2016; VončInA \& Stebel 2012; VonČInA i in. 2014; Stebel 2015).

Niniejsza praca zawiera informacje o 99 gatunkach i 1 odmianie mchów, z czego 36 gatunków (np. Anomodon attenuatus, Neckera pennata i Zygodon rupestris) jest objętych ochroną, a 10 (np. Neckera besseri, Syntrichia virescens i Tomentypnum nitens) 


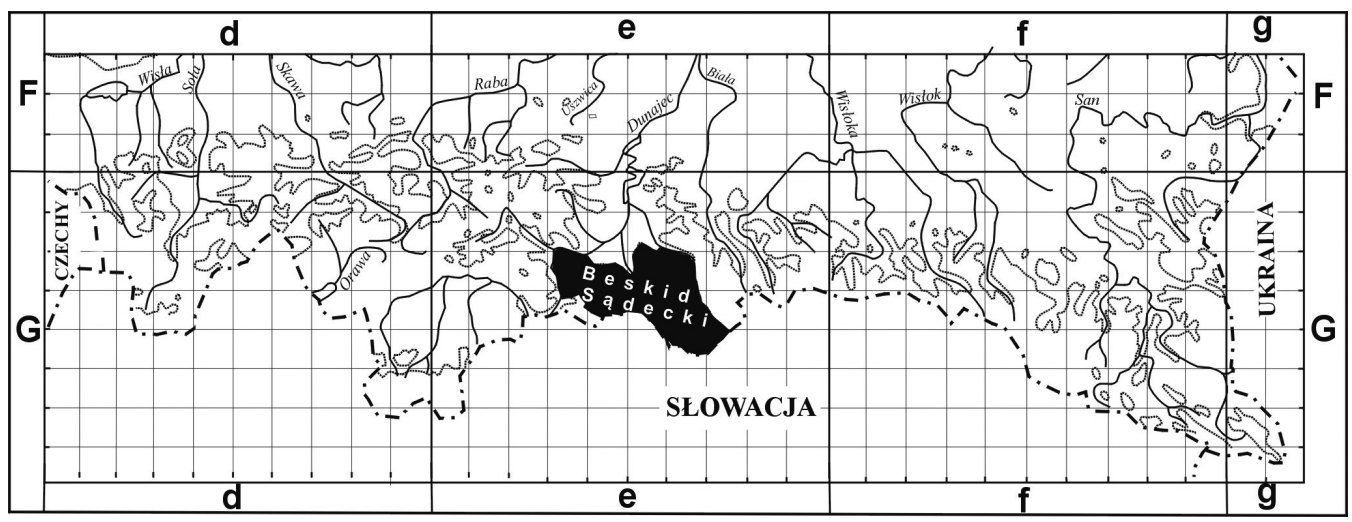

Ryc. 1. Położenie Beskidu Sądeckiego w polskiej części Karpat

Fig. 1. Location of the Beskid Sądecki range in the Polish part of the Carpathians

zagrożonych w Polsce. Jedenaście gatunków (Aloina rigida, Bryum rubens, Cirriphyllum crassinervium, Eucladium verticillatum, Fissidens rufulus, Guembelia longirostris, Schistidium lancifolium, Schistidium papillosum, Sphagnum russowii, Thamnobryum neckeroides i Tortula modica) podano po raz pierwszy z Beskidu Sądeckiego.

\section{MATERIAE I METODY}

Badania terenowe przeprowadzono w latach 2016-2020. Na poszczególnych stanowiskach notowano: wysokość nad poziomem morza, położenie geograficzne (za pomocą odbiornika GPS) oraz siedlisko. Listę gatunków, dla których nazewnictwo przyjęto za OcHYRĄ i in. (2003) zestawiono alfabetycznie. Gatunki chronione w Polsce podano za Rozporządzeniem Ministra Środowiska (2014), natomiast zagrożone za ŻARNOWCEM i in. (2004). Przy gatunkach rzadszych umieszczono informacje o ich aktualnym występowaniu w Beskidzie Sądeckim i rozmieszczeniu w polskiej części Karpat. Materiały zielnikowe złożono w Zielniku Katedry i Zakładu Botaniki Farmaceutycznej i Zielarstwa Śląskiego Uniwersytetu Medycznego w Katowicach (SOSN).

\section{LISTA GATUNKÓW}

Skróty: AS - Adam Stebel, c. gem. - z rozmnóżkami; c. spor. - ze sporofitami; dol. - dolina; GV - Grzegorz Vončina; $\mathrm{m}$ - m n.p.m.; S - południowy; N - północny; os. - osiedle; E - wschodni; W - zachodni; !! - gatunek ściśle chroniony; ! - gatunek częściowo chroniony; () - kategoria zagrożenia gatunku w Polsce: $\mathrm{E}$ - wymierający, R - rzadki, V - narażony.

! Abietinella abietina (Hedw.) M.Fleisch. - Ge 47: 49 $18^{\prime} 42^{\prime \prime} \mathrm{N}, 20^{\circ} 58^{\prime} 32^{\prime \prime} \mathrm{E}$, Dubne, kamienny murek obok cerkwi, 625 m (AS, 3.06.2018); Ge 47: 49 $18^{\prime} 00^{\prime \prime} \mathrm{N}, 20^{\circ} 56^{\prime} 13^{\prime \prime}$ E, Leluchów, kamienny murek obok cerkwi, 524 m (AS, 3.06.2018); Ge 23: 49³2'17,3"N, 20²4'37,6"E, Zarzecze, Skałki, humus na piaskowcu, murawa zarastająca Betula pendula i Pinus sylvestris, $404 \mathrm{~m}$ (GV, 16.03.2019). Gatunek światłolubny i ciepłolubny, zanikających w wielu rejonach Karpat wskutek zarastania okrajków i muraw.

Aloina rigida (Hedw.) Limpr. - Ge 46: 49 $20^{\prime} 16,9^{\prime \prime} \mathrm{N}, 20^{\circ} 53^{\prime} 53,4^{\prime \prime} \mathrm{E}$, Muszyna, os. Rusinów, gleba mineralna na piaskowcu, nieczynny kamieniołom, c. spor., $462 \mathrm{~m}$ (GV, 1.04.2017). Mech wapieniolubny, bardzo rzadki w Karpatach. Podawany z Kotliny Żywieckiej (Krupa 1879), Gorców (Kornaś \& MedwECKA-Kornaś 
1967); Pienińskiego Pasa Skałkowego (KruPa 1885; ChaŁubiński 1886; OchYRa 1984; OchYRa \& Stebel 2008; STEBel i in. 2010), Beskidu Niskiego (KARCZMARZ 1979), Dołów Jasielsko-Sanockich (ARMATA 2011) i Pogórza Przemyskiego (KarczMarz 1975). Nowy dla flory Beskidu Sądeckiego (Ryc. 2).

Amblystegium juratzkanum Schimp. - Ge 25: 49 $30^{\prime} 29,0^{\prime \prime} \mathrm{N}, 20^{\circ} 41^{\prime} 18,6^{\prime \prime} \mathrm{E}$, Rytro, przysiółek Życzanów, Głęboki Jar, dol. Życzanowskiego Potoku, gleba gliniasta, brzeg potoku, c.spor., $394 \mathrm{~m}$ (GV, 7.06.2020). W Beskidzie Sądeckim znany z 2 stanowisk (MAMCZARZ 1977).

! Anomodon attenuatus (Hedw.) Huebener - Ge 25: 49 $30^{\prime} 35,9^{\prime \prime} \mathrm{N}, 20^{\circ} 41^{\prime} 45,0^{\prime \prime} \mathrm{E}$, Rytro, przysiółek Życzanów, Głęboki Jar, dol. Życzanowskiego Potoku, piaskowiec, skały, 434 m (GV, 7.06.2020); Ge 36: $49^{\circ} 24^{\prime} 13^{\prime \prime} \mathrm{N}, 20^{\circ} 51^{\prime} 30^{\prime \prime} \mathrm{E}$, Szczawnik, dol. potoku Szczawnik, kora Fagus sylvatica, 658-680 m (AS, 2.06.2018); Ge 46: $49^{\circ} 21^{\prime} 06^{\prime \prime} \mathrm{N}, 20^{\circ} 53^{\prime} 07^{\prime} \mathrm{E}$, Muszyna, rezerwat „Obrożyska”, wychodnie skalne, $450 \mathrm{~m}$ (AS, 2.06.2018).

! Anomodon viticulosus (Hedw.) Hook. \& Taylor - Ge 36: 49 $24^{\prime} 13^{\prime \prime} \mathrm{N}, 20^{\circ} 51^{\prime} 30^{\prime \prime} \mathrm{E}$, Szczawnik, dol. potoku Szczawnik, kora Fagus sylvatica, 658-680 m (AS, 2.06.2018); Ge 46: 49²1'06"N, 2053'07"E, Muszyna, rezerwat „Obrożyska”, wychodnie skalne, 450 m (AS, 2.06.2018).

! Aulacomnium palustre (Hedw.) Schwägr. - Ge 36: 49 $23^{\prime} 10,9^{\prime \prime} \mathrm{N}, 2^{\circ} 53^{\prime} 08,7^{\prime \prime} \mathrm{E}$, Szczawnik, dol. Szczawniczka, gleba torfowa, młaka eutroficzna, $578 \mathrm{~m}$ (GV, 3.06.2017); Ge 36: 49²7'30,1"N, $20^{\circ} 49^{\prime} 28,0^{\prime \prime} \mathrm{E}$, Wierchomla Wielka, dol. potoku Potasznia, polana Młaczne, gleba torfowa, młaka eutroficzna, $740 \mathrm{~m}(\mathrm{GV}, 3.06 .2017)$. Wskutek zaniku młak gatunek coraz rzadziej obserwowany w Karpatach.

Bartramia pomiformis Hedw. - Ge 34: $49^{\circ} 26^{\prime} 40^{\prime \prime} \mathrm{N}, 20^{\circ} 30^{\prime} 21^{\prime \prime} \mathrm{E}$, Szczawnica, dol. Potoku Pod Górkami, skały piaskowca, jedlina przy potoku, c. spor., $610 \mathrm{~m}$ (GV, 5.06.2010). Rzadki w Karpatach i w Beskidzie Sądeckim (MAMCZARz 1977).

Blindia acuta (Hedw.) Bruch \& Schimp. - Ge 25: 49³0'38,2"N, 2041'52,5"E, Rytro, przysiółek Życzanów, Głęboki Jar, dol. Życzanowskiego Potoku, piaskowiec, skały, brzeg potoku, $454 \mathrm{~m}$ (GV, 7.06.2020); Ge 34: 49 $25^{\prime} 35,7^{\prime \prime} \mathrm{N}, 20^{\circ} 32^{\prime} 04,0^{\prime \prime} \mathrm{E}$, Szlachtowa, dol. Sielskiego Potoku, skały piaskowca, brzeg potoku, $595 \mathrm{~m}$ (GV, 19.06.2016). Gatunek częsty tylko w wyższych pasmach Beskidów (STEBEL 2006), w Beskidzie Sądeckim znany do tej pory z jednego stanowiska w potoku Czaczowiec (STEBEL 2015).

Brachythecium glareosum (Bruch ex Spruce) Schimp. - Ge 46: 49 $22^{\prime} 11^{\prime \prime} \mathrm{N}, 20^{\circ} 55^{\prime} 26^{\prime \prime} \mathrm{E}$, MuszynaPodjastrzębik, skarpa w zaroślach, c. spor., 488 m (AS, 2.06.2018). Rzadki w Beskidzie Sądeckim (MAMCZARZ 1977).

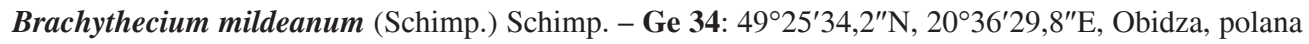
Litawcowa, gleba torfowa, młaka eutroficzna, $950 \mathrm{~m}(\mathrm{GV}, 4.06 .2017)$. Wskutek zaniku młak gatunek zanikający w Karpatach. W Beskidzie Sądeckim znany do tej pory z jednego stanowiska w rezerwacie „Łabowiec” (MicKIEWICZ 1969).

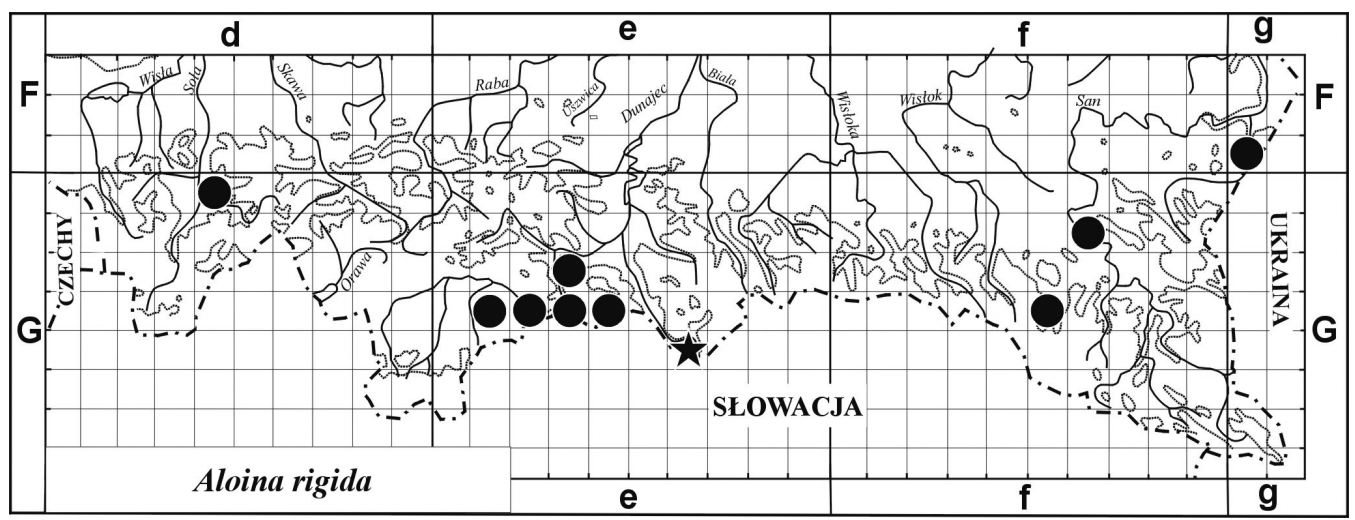

Ryc. 2. Rozmieszczenie Aloina rigida w polskiej części Karpat. Gwiazdką oznaczono nowe stanowisko

Fig. 2. Distribution of Aloina rigida in the Polish part of the Carpathians. Star indicates the new locality 
Bryum rubens Mitt. - Ge 47: 49 $18^{\prime} 42^{\prime \prime} \mathrm{N}, 20^{\circ} 58^{\prime} 32^{\prime \prime} \mathrm{E}$, Dubne, gleba w szczelinach kamiennego murku obok cerkwi, c. gem., 625 m (AS, 3.06.2018). Mech znany w Karpatach z pojedynczych stanowisk w Beskidzie Śląskim (PlášEK \& Stebel 2002), paśmie Policy (Stebel i in. 2004), Kotlinie Żywieckiej (Stebel \& Stebel 1998; Stebel 2008), Beskidzie Małym (Stebel \& Stebel 1998; Stebel 2010), Małych Pieninach (OchYra \& Stebel 2008), na Pogórzu Śląskim (Klama \& Żarnowiec 2011), Pogórzu Rożnowskim (STEBel 1999), Pogórzu Ciężkowickim (Stebel \& VonČina 2017) i Pogórzu Dynowskim (ARMata 2005). Nowy dla flory Beskidu Sądeckiego (Ryc. 3).

! Buckiella undulata (Hedw.) Ireland - Ge 47: 49 $22^{\prime} 39^{\prime \prime} \mathrm{N}, 20^{\circ} 58^{\prime} 05^{\prime \prime} \mathrm{E}$, Powroźnik, skarpa w jedlinie, 593 m (AS, 5.05.2018). Częsty w zachodniej części Beskidów (Stebel 2006), w Beskidzie Sądeckim bardzo rzadki (MAMCZARZ 1977).

Callicladium haldanianum (Grev.) H.A.Crum - Ge 25: 49 $30^{\prime} 35,9^{\prime \prime} \mathrm{N}, 20^{\circ} 41^{\prime} 45,0^{\prime \prime} \mathrm{E}$, Rytro, przysiółek Życzanów, Głęboki Jar, dol. Życzanowskiego Potoku, próchniejące drewno Abies alba, $434 \mathrm{~m}$ (GV, 7.06.2020); Ge 47: 49 $22^{\prime} 31^{\prime \prime} \mathrm{N}, 20^{\circ} 58^{\prime} 10^{\prime \prime} \mathrm{E}$, Powroźnik, murszejące drewno w jedlinie obok niebieskiego szlaku, c. spor., 671 m (AS, 5.05.2018). Bardzo rzadki w Beskidzie Sądeckim (MAMCZARZ 1977).

! Calliergonella cuspidata (Hedw.) Loeske - Ge 34: 49 $25^{\prime} 34,2^{\prime \prime} \mathrm{N}, 20^{\circ} 36^{\prime} 29,8^{\prime \prime} \mathrm{E}$, Obidza, polana Litawcowa, gleba torfowa, młaka eutroficzna, $950 \mathrm{~m}$ (GV, 4.06.2017); Ge 36: 49 $23^{\prime} 10,9^{\prime \prime} \mathrm{N}, 20^{\circ} 53^{\prime} 08,7^{\prime \prime} \mathrm{E}$, Szczawnik, dol. Szczawniczka, gleba torfowa, młaka eutroficzna, 578 m (GV, 3.06.2017); Ge 36: $49^{\circ} 27^{\prime} 30,1^{\prime \prime} \mathrm{N}, 20^{\circ} 49^{\prime} 28,0^{\prime \prime} \mathrm{E}$, Wierchomla Wielka, dol. potoku Potasznia, polana Młaczne, gleba torfowa,

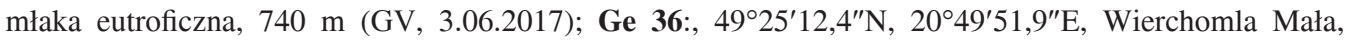
polana Wyżnie Młaki, gleba torfowa, młaka eutroficzna, $790 \mathrm{~m}$ (GV, 3.06.2017); Ge 47: 49²1'59"N, $20^{\circ} 59^{\prime} 02^{\prime \prime} \mathrm{E}$, Powroźnik, obok drogi do Tylicza, przydrożna skarpa, $523 \mathrm{~m}$ (AS, 5.05.2018); Ge 47: $49^{\circ} 22^{\prime} 37^{\prime \prime} \mathrm{N}, 21^{\circ} 00^{\prime} 33^{\prime \prime} \mathrm{E}$, Tylicz, obok drogi do Powroźnika, las mieszany, $551 \mathrm{~m}$ (AS, 5.05.2018); Ge 47: $49^{\circ} 18^{\prime} 42^{\prime \prime} \mathrm{N}, 20^{\circ} 58^{\prime} 32^{\prime \prime} \mathrm{E}$, Dubne, kamienny murek obok cerkwi, 625 m (AS, 3.06.2018).

Campyliadelphus chrysophyllus (Brid.) R.S.Chopra - Ge 23: 49³2'17,3"N, 20²4'37,6"E, Zarzecze, Skałki, glina na piaskowcu, zarośla Betula pendula i Pinus sylvestris, $404 \mathrm{~m}$ (GV, 16.03.2019). Gatunek zanikający w wielu rejonach Karpat wskutek zarastania okrajków i muraw.

Campylium stellatum (Hedw.) Lange \& C.E.O.Jensen var. stellatum - Ge 36: $49^{\circ} 23^{\prime} 10,9^{\prime \prime} \mathrm{N}$, $20^{\circ} 53^{\prime} 08,7^{\prime \prime E}$, Szczawnik, dol. Szczawniczka, gleba torfowa, młaka eutroficzna, 578 m (GV, 3.06.2017); Ge 36: $49^{\circ} 25^{\prime} 12,4^{\prime \prime} \mathrm{N}, 20^{\circ} 49^{\prime} 51,9^{\prime \prime} \mathrm{E}$, Wierchomla Mała, polana Wyżnie Młaki, gleba torfowa, młaka eutroficzna, $790 \mathrm{~m}$ (GV, 3.06.2017). Wskutek zaniku młak gatunek coraz rzadziej obserwowany w Karpatach.

Campylium stellatum var. protensum (Brid.) Bryhn - Ge 25: 49 $30^{\prime} 29,0^{\prime \prime} \mathrm{N}, 20^{\circ} 41^{\prime} 18,6^{\prime \prime} \mathrm{E}$, Rytro, przysiółek Życzanów, Głęboki Jar, dol. Życzanowskiego Potoku, gleba gliniasta, brzeg potoku, $394 \mathrm{~m}$ (GV, 7.06.2020). Odmiana bardzo rzadka w Beskidzie Sądeckim (MaMcZARz 1977).

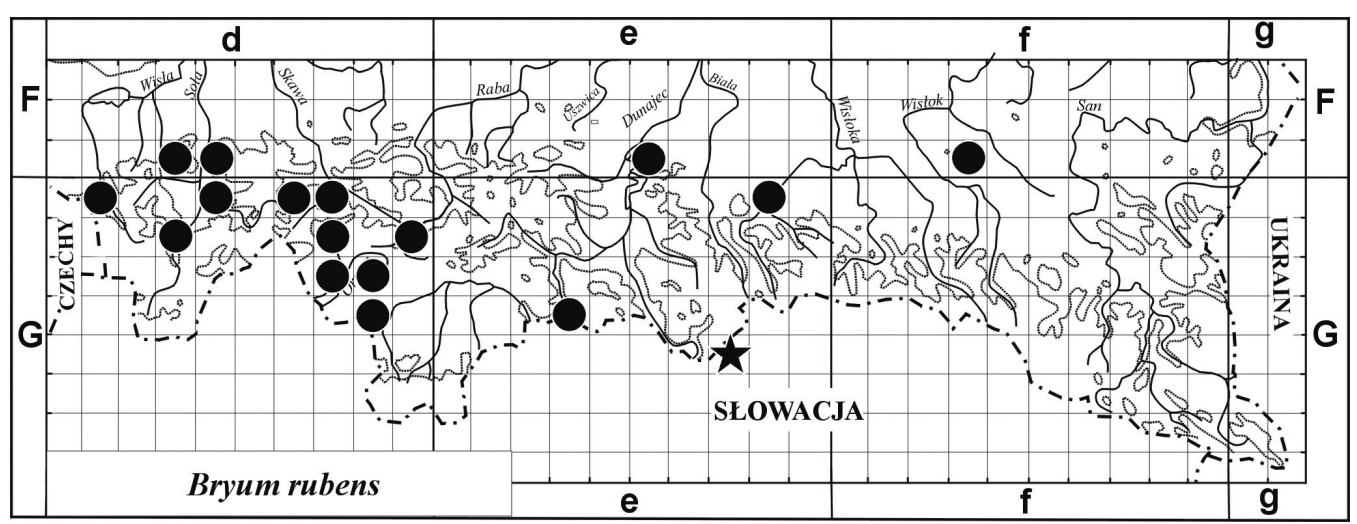

Ryc. 3. Rozmieszczenie Bryum rubens w polskiej części Karpat. Gwiazdką oznaczono nowe stanowisko

Fig. 3. Distribution of Bryum rubens in the Polish part of the Carpathians. Star indicates the new locality 
Campylophyllopsis calcarea (Crundwell \& Nyholm) Ochyra - Ge 23: 49 32'17,3"N, 20²4'37,6"E, Zarzecze, Skałki, zwietrzelina piaskowca, zarośla Betula pendula i Pinus sylvestris, 404 m (GV, 16.03.2019). Gatunek wapieniolubny, rzadki w Karpatach i Beskidzie Sądeckim (MAMCZARZ 1977).

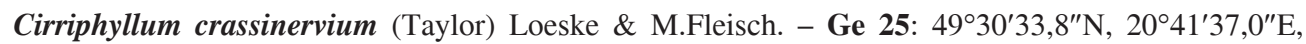
Rytro, przysiółek Życzanów, Głęboki Jar, dol. Życzanowskiego Potoku, zwietrzelina piaskowca, skarpa potoku, $419 \mathrm{~m}$ (GV, 7.06.2020). Gatunek nowy dla Beskidu Sądeckiego, w Karpatach znany do tej pory tylko z Pienińskiego Pasa Skałkowego (OCHYRA i in. 1988; Stebel i in. 2010).

! Climacium dendroides (Hedw.) F.Weber \& D.Mohr - Ge 34: 49 $25^{\prime} 34,2^{\prime \prime} \mathrm{N}, 20^{\circ} 36^{\prime} 29,8^{\prime \prime} \mathrm{E}$, Obidza, polana Litawcowa, gleba torfowa, młaka eutroficzna, $950 \mathrm{~m}$ (GV, 4.06.2017); Ge 35: 49 $27^{\prime} 44,4^{\prime \prime} \mathrm{N}$, $20^{\circ} 45^{\prime} 03,7^{\prime \prime E}$, Łomnica-Zdrój, polana powyżej os. Do Potoka, gleba torfowa, młaka eutroficzna, $725 \mathrm{~m}$ (GV, 4.06.2017); Ge 36: 49 $23^{\prime} 10,9^{\prime \prime} \mathrm{N}, 2^{\circ} 53^{\prime} 08,7^{\prime \prime} \mathrm{E}$, Szczawnik, dol. Szczawniczka, gleba torfowa, młaka eutroficzna, $578 \mathrm{~m}$ (GV, 3.06.2017); Ge 36: 49 $27^{\prime} 30,1^{\prime \prime} \mathrm{N}, 20^{\circ} 49^{\prime} 28,0^{\prime \prime} \mathrm{E}$, Wierchomla Wielka, dol. potoku Potasznia, polana Młaczne, gleba torfowa, młaka eutroficzna, $740 \mathrm{~m}$ (GV, 3.06.2017); Ge 36: $49^{\circ} 25^{\prime} 12,4^{\prime \prime} \mathrm{N}, 20^{\circ} 49^{\prime} 51,9^{\prime \prime} \mathrm{E}$, Wierchomla Mała, polana Wyżnie Młaki, gleba torfowa, młaka eutroficzna, 790 m (GV, 3.06.2017); Ge 47: 49 $18^{\prime} 42^{\prime \prime} \mathrm{N}, 2^{\circ} 58^{\prime} 32^{\prime \prime} \mathrm{E}$, Dubne, kamienny murek obok cerkwi, $625 \mathrm{~m}$ (AS, 3.06.2018); Ge 47: 49 $21^{\prime} 51^{\prime \prime} \mathrm{N}, 20^{\circ} 58^{\prime} 20^{\prime \prime}$ E, Powroźnik, zapora na potoku Słupne (=Stupne), zarośla obok zapory, $510 \mathrm{~m}$ (AS, 5.05.2018).

!Ctenidium molluscum (Hedw.) Mitt. - Ge 25: 49³0'35,9"N $20^{\circ} 41^{\prime} 45,0^{\prime \prime} \mathrm{E}$, Rytro, przysiółek Życzanów, Głęboki Jar, dol. Życzanowskiego Potoku, piaskowiec, skały, 434 m (GV, 7.06.2020); Ge 47: $49^{\circ} 21^{\prime} 59^{\prime \prime} \mathrm{N}, 20^{\circ} 59^{\prime} 02^{\prime \prime} \mathrm{E}$, Powroźnik, obok drogi do Tylicza, przydrożna skarpa, $523 \mathrm{~m}$ (AS, 5.05.2018).

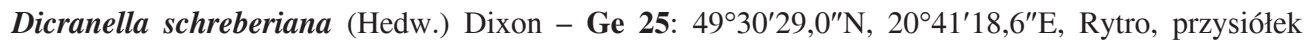
Życzanów, Głęboki Jar, dol. Życzanowskiego Potoku, gleba gliniasta, brzeg potoku, $394 \mathrm{~m}$ (GV, 7.06.2020). W Beskidzie Sądeckim znany do tej pory z jednego stanowiska w rezerwacie „Łabowiec” (MAMCZARZ 1977).

! Dicranum scoparium Hedw. - Ge 37: 4926 $36^{\prime \prime} \mathrm{N}, 20^{\circ} 56^{\prime} 49^{\prime \prime} \mathrm{E}$, Krynica-Słotwiny, jedlina, 689-708 m (AS, 5.05.2018).

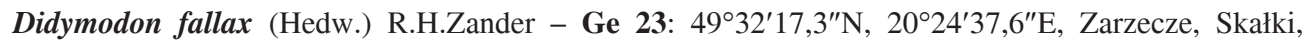
zwietrzelina piaskowca, zarośla Betula pendula i Pinus sylvestris, $404 \mathrm{~m}$ (GV, 16.03.2019); Ge 25: 49 30'29,0'N, 2041'18,6"E, Rytro, przysiółek Życzanów, Głęboki Jar, dol. Życzanowskiego Potoku, gleba gliniasta, brzeg potoku, c.spor., 394 m (GV, 7.06.2020). Gatunek w Beskidach Zachodnich znany $\mathrm{z}$ rozproszonych stanowisk (STEBEL 2006).

Didymodon ferrugineus (Schimp. ex Besch.) M.O.Hill - Ge 23: 49³2'17,3"N, 20²4'37,6" E, Zarzecze, Skałki, zwietrzelina piaskowca, zarośla Betula pendula i Pinus sylvestris, $404 \mathrm{~m}$ (GV, 16.03.2019); Ge 25: 49³0'35,9"N, 2041'45,0"E, Rytro, przysiółek Życzanów, Głęboki Jar, dol. Życzanowskiego Potoku, piaskowiec, skały, 434 m (GV, 7.06.2020). Gatunek rzadki w Beskidzie Sądeckim (MAMCZARZ 1977; STEBEL 2015).

Didymodon rigidulus Hedw. - Ge 23: 49 $32^{\prime} 17,3^{\prime \prime} \mathrm{N}, 20^{\circ} 24^{\prime} 37,6^{\prime \prime} \mathrm{E}$, Zarzecze, Skałki, zwietrzelina piaskowca, zarośla Betula pendula i Pinus sylvestris, c. gem., 404 m (GV, 16.03.2019); Ge 25: 49³0'35,9"N, $20^{\circ} 41^{\prime} 45,0^{\prime \prime} E$, Rytro, przysiółek Życzanów, Głęboki Jar, dol. Życzanowskiego Potoku, piaskowiec, skały, c.spor., 434 m (GV, 7.06.2020). Gatunek częsty w Beskidach Zachodnich (STEBEL 2006), z Beskidu Sądeckiego do tej pory podawany rzadko (MAMCZARZ 1977).

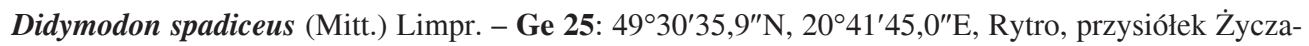
nów, Głęboki Jar, dol. Życzanowskiego Potoku, piaskowiec, skały, skarpa potoku, 434 m (GV, 7.06.2020). W Beskidzie Sądeckim bardzo rzadki, znany z 3 stanowisk (MAMCZarz 1977; STEBel 2015).

Diphyscium foliosum (Hedw.) D.Mohr - Ge 46: 49 $20^{\prime} 51^{\prime \prime} \mathrm{N}, 20^{\circ} 52^{\prime} 41^{\prime \prime} \mathrm{E}$, Muszyna, rezerwat „Obrożyska", gleba mineralna, przydroże, c. spor., $470 \mathrm{~m}$ (AS, 3.06.2018); Ge 25: 49³0'32,6"N, 2041'13,6"E, Rytro, przysiółek Życzanów, os. Głęboki Jar, gleba mineralna, przydroże, buczyna karpacka, $408 \mathrm{~m}$ (GV, 17.06.2016). W Beskidzie Sądeckim znany z rozproszonych stanowisk (MAMCZARz 1977; VonČINA \& STEBEL 2012). 
Ditrichum flexicaule (Schwägr.) Hampe - Ge 47: 49²1'54"N, 2058'21"E, Powroźnik, zapora na potoku Słupne, ocienione głazy muru zapory, $508 \mathrm{~m}$ (AS, 5.05.2018); Ge 23: 49³2' 17,3"N, 20²4'37,6" E, Zarzecze, Skałki, humus na piaskowcu, zarośla Betula pendula i Pinus sylvestris, 404 m (GV, 16.03.2019). W Beskidzie Sądeckim podawany z rozproszonych stanowisk (MAMCZARz 1977).

Dryptodon hartmanii (Schimp.) Limpr. - Ge 33: 49 $27^{\prime} 28,3^{\prime \prime} \mathrm{N}, 20^{\circ} 30^{\prime} 22,9^{\prime \prime} \mathrm{E}$, Szczawnica, Czeremcha Zachodnia, skały piaskowca, jedlina, c. gem., $872 \mathrm{~m}$ (GV, 27.10.2018). Bardzo rzadki w Beskidzie Sądeckim (MAMCZARZ 1977).

Dryptodon pulvinatus (Hedw.) Brid. - Ge 23: 49³2'17,3"N, 20²4'37,6"'E, Zarzecze, Skałki, piaskowiec, zarośla Betula pendula i Pinus sylvestris, c. spor., $404 \mathrm{~m}$ (GV, 16.03.2019). Z Beskidu Sądeckiego podawany z rozproszonych stanowisk (MAMCZARZ 1977).

Encalypta streptocarpa Hedw. - Ge 25: 49³0'35,9"N, 2041'45,0"E, Rytro, przysiółek Życzanów, Głęboki Jar, dol. Życzanowskiego Potoku, piaskowiec, szczeliny skał, c.gem., 434 m (GV, 7.06.2020). W Beskidzie Sądeckim znany z rozproszonych stanowisk (MAMCZARZ 1977).

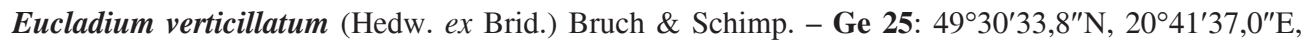
Rytro, przysiółek Życzanów, Głęboki Jar, dol. Życzanowskiego Potoku, martwica wapienna, mszarnik, skarpa potoku, $419 \mathrm{~m}$ (GV, 7.06.2020). Gatunek nowy dla Beskidu Sądeckiego, rzadki w Karpatach, ostatnio odnaleziony w Górach Sanocko-Turczańskich (FoJcik i in. 2017).

!Eurhynchium angustirete (Broth.) T.J.Kop. - Ge 23: 49 $32^{\prime} 17,3^{\prime \prime} \mathrm{N}, 20^{\circ} 24^{\prime} 37,6^{\prime \prime} \mathrm{E}$, Zarzecze, Skałki, humus na piaskowcu, zarośla Betula pendula i Pinus sylvestris, 404 m (GV, 16.03.2019); Ge 37: 49 $26^{\prime} 36^{\prime \prime} \mathrm{N}, 20^{\circ} 56^{\prime} 49^{\prime \prime} \mathrm{E}$, Krynica-Słotwiny, źródliska w jedlinie, 689 m (AS, 5.05.2018); Ge 47: $49^{\circ} 21^{\prime} 59^{\prime \prime} \mathrm{N}, 20^{\circ} 59^{\prime} 02^{\prime \prime} \mathrm{E}$, Powroźnik, obok drogi do Tylicza, przydrożna skarpa, $523 \mathrm{~m}$ (AS, 5.05.2018); Ge 47: 49 $22^{\prime} 34^{\prime \prime} \mathrm{N}, 20^{\circ} 57^{\prime} 49^{\prime \prime} \mathrm{E}$, Powroźnik, skarpa w zaroślach obok niebieskiego szlaku turystycznego,

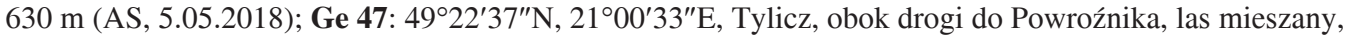
$551 \mathrm{~m}$ (AS, 5.05.2018).

Fissidens dubius P.Beauv. var. mucronatus (Breidl. ex Limpr.) Karttunen, Hedenäs \& Söderström - Ge 23: 49 32'17,3"N, 20²4'37,6"E, Zarzecze, Skałki, humus na piaskowcu, zarośla Betula pendula i Pinus sylvestris, $404 \mathrm{~m}(\mathrm{GV}, 16.03 .2019)$. Odmiana rośnie w Karpatach na rozproszonych stanowiskach, z terenu Beskidu Sądeckiego podawana z dwóch stanowisk (BRYLSKA 1991; VonČINA w: GóRSKI i in. 2016).

Fissidens rufulus Schimp. - Ge 23: 49³0'12,9"N/20²4'01,9"E, Tylmanowa, os. Kozuby, koryto Dunajca, szczelina piaskowca obmywanego wodą, $393 \mathrm{~m}$ (GV, 13.02.2016); Ge 45: 49²3'06,9"N/20 45'34,9" E, Zubrzyk, koryto Popradu, szczelina piaskowca obmywanego wodą, c.spor., $382 \mathrm{~m}$ (GV, 1.04.2017). Gatunek nowy dla Beskidu Sądeckiego, rzadki w Karpatach. Ostatnio podany z rezerwatu „Przełom Osławy pod Duszatynem" w Bieszczadach Zachodnich (STEBel i in. 2020).

Fontinalis antipyretica Hedw. - Ge 47: 49 $22^{\prime} 44^{\prime \prime} \mathrm{N}, 21^{\circ} 00^{\prime} 24^{\prime \prime} \mathrm{E}$, Tylicz, głazy w Muszynce, $548 \mathrm{~m}$ (AS, 5.05.2018). Mech bardzo rzadki w Beskidzie Sądeckim (MAMCZARZ 1977).

Guembelia longirostris (Hook.) Ochyra \& Żarnowiec - Ge 33: 49 27'18,9"N, 20³0'12,7"E Szczawnica, Czeremcha Zachodnia, skały piaskowca, jedlina, c. spor., $779 \mathrm{~m}(\mathrm{GV}, 27.10 .2018)$. Mech rosnący na rozproszonych stanowiskach w Karpatach, nowy dla Beskidu Sądeckiego.

Gymnostomum aeruginosum Sm. - Ge 25: 49³0'35,7"N, 2041'42,3"E, Rytro, przysiółek Życzanów, dolina Potoku Rzeczanowskiego, ocienione skały piaskowca nad brzegiem potoku w Dentario glandulosae-Fagetum, 420 m (GV, 17.06.2016). Gatunek podany przy opisie stanowiska Dicranum viride (STEBEL i in. 2018), nowy dla flory Beskidu Sądeckiego, w Karpatach znany głównie z Pienin (OchYRA 1984; OchYRA \& STEBel 2008; STEBel i in. 2010).

Hedwigia ciliata (Hedw.) P.Beauv. - Ge 33: 49 $27^{\prime} 18,9^{\prime \prime} \mathrm{N}, 20^{\circ} 30^{\prime} 12,7^{\prime \prime} \mathrm{E}$, Szczawnica, Czeremcha Zachodnia, skały piaskowca, jedlina, c. spor., $779 \mathrm{~m}$ i $49^{\circ} 27^{\prime} 28,3^{\prime \prime} \mathrm{N}, 20^{\circ} 30^{\prime} 22,9^{\prime \prime} \mathrm{E}$, c. spor., $872 \mathrm{~m}(\mathrm{GV}$, 27.10.2018); Ge 36: 49 $24^{\prime} 13^{\prime \prime} N$, 20 ${ }^{\circ} 51^{\prime} 28^{\prime \prime}$ E, Szczawnik, dol. potoku Szczawnik, wychodnie skalne, c. spor., 670-680 m (AS, 2.06.2018). W Beskidzie Sądeckim znany z rozproszonych stanowisk (MAMCZARZ 1977). 


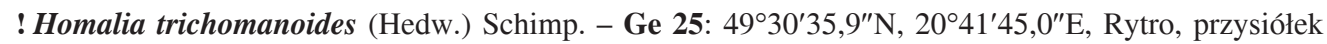
Życzanów, Głęboki Jar, dol. Życzanowskiego Potoku, piaskowiec, skały, 419 m, 434 m (GV, 7.06.2020); Ge 36: 49²4'14"N, 2051'28"E, Szczawnik, dol. potoku Szczawnik, pień Fagus sylvatica, c. spor., 658 m (AS, 2.06.2018). Bardzo rzadki w Beskidzie Sądeckim (MAMCZarz 1977; Stebel 2015).

Homalothecium philippeanum (Spruce) Schimp. - Ge 36: 49 $24^{\prime} 13^{\prime \prime} \mathrm{N}, 20^{\circ} 51^{\prime} 28^{\prime \prime} \mathrm{E}$, Szczawnik, dol. potoku Szczawnik, wychodnie skalne, 670-680 m (AS, 2.06.2018). W Karpatach (z wyjątkiem Pienin i Tatr Zachodnich) bardzo rzadki, w Beskidzie Sądeckim znany z pojedynczych stanowisk (MAMCZARZ 1977).

Homomallium incurvatum (Schrad. ex Brid.) Loeske - Ge 23: 49³2'17,3"N, 20²4'37,6"E, Zarzecze, Skałki, zwietrzelina piaskowca, zarośla Betula pendula i Pinus sylvestris, c. spor., 404 m (GV, 16.03.2019); Ge 25: 49³0'38,2"N, 2041'52,5"E, Rytro, przysiółek Życzanów, Głęboki Jar, dol. Życzanowskiego Potoku, piaskowiec, skały, skarpa potoku, c.spor., $454 \mathrm{~m}$ (GV, 7.06.2020). Gatunek bardzo rzadki w Beskidzie Sądeckim (MamcZarz 1977; Stebel 2015).

! Hylocomiastrum triquetrum (Hedw.) Ochyra \& Stebel - Ge 47: 49²1'59"N, 2059'02"E, Powroźnik, obok drogi do Tylicza, przydrożna skarpa, $523 \mathrm{~m}$ (AS, 5.05.2018); Ge 47: 49 $21^{\prime} 51^{\prime \prime} \mathrm{N}, 20^{\circ} 58^{\prime} 20^{\prime \prime} \mathrm{E}$, Powroźnik, zapora na potoku Słupne, zarośla obok zapory, 510 m (AS, 5.05.2018); Ge 47: 49²2'27"N, $20^{\circ} 57^{\prime} 12^{\prime \prime} \mathrm{E}$, Powroźnik, skarpa w zaroślach obok niebieskiego szlaku turystycznego, $516 \mathrm{~m}$ (AS, 5.05.2018).

! Hylocomium splendens (Hedw.) Schimp. - Ge 46: 49 $19^{\prime} 31^{\prime \prime} \mathrm{N}, 20^{\circ} 54^{\prime} 19^{\prime \prime} \mathrm{E}$, Muszyna-Majdan, skarpa

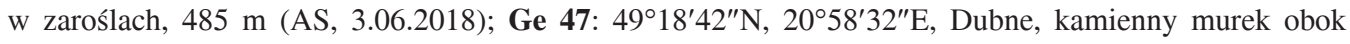
cerkwi, 625 m (AS, 3.06.2018); Ge 47: 49²1'59"N, 2059'02"E, Powroźnik, obok drogi do Tylicza, przydrożna skarpa, 523 m (AS, 5.05.2018); Ge 47: 49²2'27"N, 2057'12"E, Powroźnik, skarpa w zaroślach obok niebieskiego szlaku turystycznego, $516 \mathrm{~m}$ (AS, 5.05.2018).

Hymenoloma crispulum (Hedw.) Ochyra - Ge 33: 49 27'28,3"N, 20³0'22,9"E, Szczawnica, Czeremcha Zachodnia, skały piaskowca, jedlina, c. spor., $872 \mathrm{~m}$ (GV, 27.10.2018). Bardzo rzadki w Beskidzie Sądeckim (OchYRA i in. 2008; STEBEL 2015).

! Leucobryum glaucum (Hedw.) Ångstr. - Ge 25: 49³0'38,2"N, 2041'52,5"E, Rytro, przysiółek Życzanów, Głęboki Jar, dol. Życzanowskiego Potoku, próchniejące drewno Abies alba, 454 m (GV, 7.06.2020).

! Limprichtia cossonii (Schimp.) L.E.Anderson - Ge 36: 49²3'10,9"N, 2053'08,7"E, Szczawnik, dol. Szczawniczka, gleba torfowa, młaka eutroficzna, $578 \mathrm{~m}$ (GV, 3.06.2017). Wskutek zaniku młak gatunek w Karpatach zmniejsza liczbę stanowisk. Bardzo rzadki w Beskidzie Sądeckim (MAMCZARZ 1977; SteBEL \& VONČINA 2011).

Mnium hornum Hedw. - Ge 25: 49 30'32,6"N, 2041'13,6"E, Rytro, przysiółek Życzanów, os. Głęboki Jar, gleba mineralna, przydroże, buczyna karpacka, 408 m (GV, 17.06.2016). Mech częstszy w zachodniej części Karpat (OchYRA i in. 2020), bardzo rzadki w Beskidzie Sądeckim (MaMCZARZ 1977; STEBEL 2015).

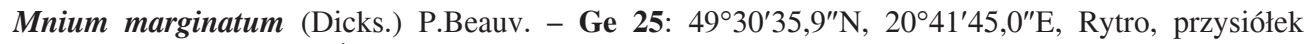
Życzanów, Głęboki Jar, dol. Życzanowskiego Potoku, szczeliny piaskowca, skały, skarpa potoku, 419 m, 434 m (GV, 7.06.2020). W Beskidzie Sądeckim bardzo rzadki (MamcZarZ 1977; STebel 2015).

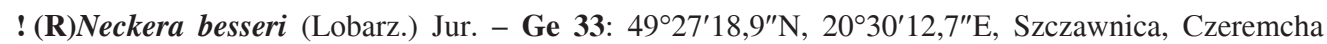
Zachodnia, skały piaskowca, jedlina, 779 m (GV, 27.10.2018); Ge 36: 49²4'13"N, 2051'28"E, Szczawnik, dol. potoku Szczawnik, wychodnie skalne, 670-680 m (AS, 2.06.2018). Mech znany z rozproszonych stanowisk w Karpatach, liczba jego notowań w ostatnich latach rośnie (OchYRA i in. 2020), w Beskidzie Sądeckim bardzo rzadki (MAMCZARZ 1977; STEBEL 2015).

! Neckera complanata (Hedw.) Huebener - Ge 25: 49³0'33,8'N, 2041'37,0"E, Rytro, przysiółek Życzanów, Głęboki Jar, dol. Życzanowskiego Potoku, piaskowiec, skały, 419 m (GV, 7.06.2020); Ge 33: $49^{\circ} 27^{\prime} 14,9^{\prime \prime} \mathrm{N}, 20^{\circ} 30^{\prime} 09,7^{\prime \prime} \mathrm{E}$, Szczawnica, Czeremcha Zachodnia, skały piaskowca, jedlina, $736 \mathrm{~m}$ (GV, 27.10.2018). Gatunek rzadki w Beskidzie Sądeckim (MAMCZARZ 1977; STEBel 2015).

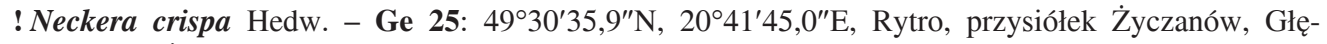
boki Jar, dol. Życzanowskiego Potoku, piaskowiec, skały, $434 \mathrm{~m}$ (GV, 7.06.2020); Ge 36: 49²4'13"N, 
$20^{\circ} 51^{\prime 2} 28^{\prime \prime E}$, Szczawnik, dol. potoku Szczawnik, wychodnie skalne, 670-680 m (AS, 2.06.2018). Gatunek rzadki w Beskidzie Sądeckim (MamcZarz 1977; STEBel 2015).

!! (E)Neckera pennata Hedw. - Ge 35: 49 $27^{\prime} 56,6^{\prime \prime} \mathrm{N}, 20^{\circ} 46^{\prime} 41,3^{\prime \prime} \mathrm{E}$, Łomnica-Zdrój, dol. potoku Łomniczanka, kora Fagus sylvatica, buczyna karpacka, 706 m (GV, 8.04.2018). Mech bardzo rzadki w Karpatach i Beskidzie Sądeckim (MAMCZARZ 1977).

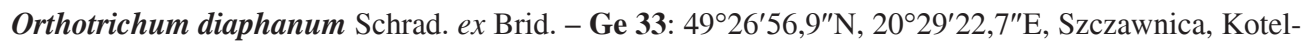
nica, zachodni stok, kora buka, buczyna karpacka, c. spor., 798 m (GV, 9.12.2018). Mech coraz częściej notowany w różnych regionach Karpat (OCHYRA i in. 2020), w Beskidzie Sądeckim rzadki (MAMCZARZ 1977; STEBel 2015).

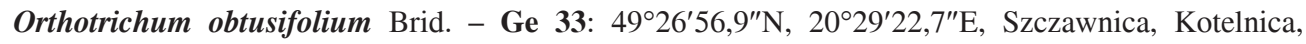
W stok, kora Fagus sylvatica, buczyna karpacka, c. gem., 798 m (GV, 9.12.2018). Mech coraz częściej notowany różnych regionach Karpat, w Beskidzie Sądeckim znany z rozproszonych stanowisk (MAMCZARZ 1977; STEBEL 2015).

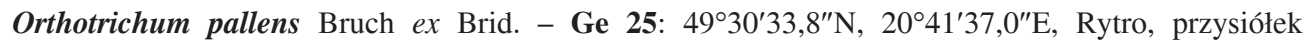
Życzanów, Głęboki Jar, dol. Życzanowskiego Potoku, piaskowiec, zwietrzelina skały, c.spor., 419 m (GV, 7.06.2020); Ge 33: 49 $26^{\prime} 56,9^{\prime \prime} \mathrm{N}, 2^{\circ} 29^{\prime} 22,7^{\prime \prime} \mathrm{E}$, Szczawnica, Kotelnica, kora Fagus sylvatica, buczyna karpacka, c. spor., $798 \mathrm{~m}$ (GV, 9.12.2018). Mech coraz częściej notowany różnych regionach Karpat (OCHYRA i in. 2020), niedawno odnaleziony także w Beskidzie Sądeckim (STEBEL 2015).

Orthotrichum speciosum Nees - Ge 47: 49 $22^{\prime} 51^{\prime \prime} \mathrm{N}, 20^{\circ} 57^{\prime} 10^{\prime \prime} \mathrm{E}$, Powroźnik, kora Fagus sylvatica, przydroże, c. spor., $502 \mathrm{~m}$ (AS, 5.05.2018). Mech coraz częściej notowany różnych regionach Karpat, w Beskidzie Sądeckim znany z rozproszonych stanowisk (MAMCZARz 1977; STEBEL 2015).

(V)Orthotrichum stramineum Hornsch. ex Brid. - Ge 33: 49 $26^{\prime} 56,9^{\prime \prime} \mathrm{N}, 20^{\circ} 29^{\prime} 22,7^{\prime \prime} \mathrm{E}$, Szczawnica, Kotelnica, kora Fagus sylvatica, buczyna karpacka, c. spor., $798 \mathrm{~m}(\mathrm{GV}, 9.12 .2018)$; Ge 34: 49²6'44,6"' N, 20³8'24,7"E, Piwniczna, przy polanie Kramarka, kora Fagus sylvatica, kwaśna buczyna, c. spor., 990 m (GV, 18.06.2016); Ge 36: 49²4'13"N, 2051'30"E, Szczawnik, dol. potoku Szczawnik, kora Fagus sylvatica, c. spor., 670-680 m (AS, 2.06.2018); Ge 36: 49 $26^{\prime} 31,4^{\prime \prime} \mathrm{N}, 20^{\circ} 49^{\prime} 43,9^{\prime \prime} \mathrm{E}$, Wierchomla Mała, Lembarczek, kora Fagus sylvatica, buczyna, c. spor., 910 m (GV, 17.03.2019).Mech coraz częściej notowany różnych regionach Karpat (OCHYRA i in. 2020), w Beskidzie Sądeckim znany z rozproszonych stanowisk (MAMCZARZ 1977; STEBEL 2015).

(V)Orthotrichum striatum Hedw. - Ge 34: 49²6'44,6" N, 20³8'24,7"E, Piwniczna, przy polanie Kramarka, kora buka, kwaśna buczyna, c. spor., 990 m (GV, 18.06.2016). Mech coraz częściej notowany różnych regionach Karpat (OchYRA i in. 2020), w Beskidzie Sądeckim rzadki (MAMCZARz 1977).

! Palustriella commutata (Hedw.) Ochyra - Ge 25: 49 $30^{\prime} 38,2^{\prime \prime} \mathrm{N}, 20^{\circ} 41^{\prime} 52,5^{\prime \prime} \mathrm{E}$, Rytro, przysiółek Życzanów, Głęboki Jar, dol. Życzanowskiego Potoku, piaskowiec, wilgotne skały, brzeg potoku, $419 \mathrm{~m}$, $454 \mathrm{~m}(\mathrm{GV}, 7.06 .2020)$; Ge 37: 49 $26^{\prime} 36^{\prime \prime} \mathrm{N}, 2^{\circ} 56^{\prime} 49^{\prime \prime} \mathrm{E}$, Krynica-Słotwiny, źródliska w jedlinie, $689 \mathrm{~m}$ (AS, 5.05.2018); Ge 47: 49 21'54"N, 2058'21"E, Powroźnik, zapora na potoku Słupne, wysięk wody,

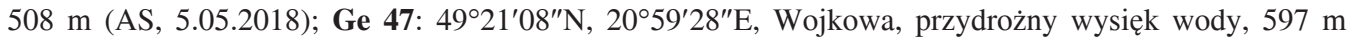
(AS, 5.05.2018).

!Philonotis calcarea (Bruch \& Schimp.) Schimp. - Ge 34: 49 $24^{\prime} 33,4^{\prime \prime} \mathrm{N}, 20^{\circ} 36^{\prime} 02,4^{\prime \prime} \mathrm{E}$, Jaworki, dolina Białej Wody, W zbocza Hrucałki, gleba mineralna ociekająca wodą, skarpa drogi w świerczynie,

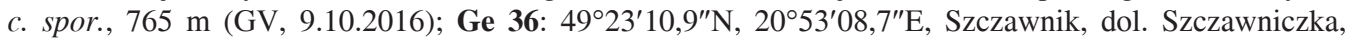
gleba torfowa, młaka eutroficzna, c. spor., $578 \mathrm{~m}(\mathrm{GV}, 3.06 .2017)$. Mech znany z rozproszonych stanowisk w Karpatach, wskutek zaniku młak coraz rzadziej obserwowany.

Plagiomnium elatum (Bruch \& Schimp.) T.J.Kop. - Ge 35: 49²7'44,4"N, 2045'03,7"E, Łomnica-Zdrój, polana powyżej os. Do Potoka, gleba torfowa, młaka eutroficzna, 725 m (GV, 4.06.2017); Ge 36: $49^{\circ} 23^{\prime} 10,9^{\prime \prime} \mathrm{N}, 20^{\circ} 53^{\prime} 08,7^{\prime \prime} \mathrm{E}$, Szczawnik, dol. Szczawniczka, gleba torfowa, młaka eutroficzna, $578 \mathrm{~m}$ (GV, 3.06.2017); Ge 36: 49 $27^{\prime} 30,1^{\prime \prime} \mathrm{N}, 20^{\circ} 49^{\prime} 28,0^{\prime \prime} \mathrm{E}$, Wierchomla Wielka, dol. potoku Potasznia, polana Młaczne, gleba torfowa, młaka eutroficzna, $740 \mathrm{~m}(\mathrm{GV}, 3.06 .2017)$; Ge 36: $49^{\circ} 25^{\prime} 12,4^{\prime \prime} \mathrm{N}$, 2049'51,9"E, Wierchomla Mała, polana Wyżnie Młaki, gleba torfowa, młaka eutroficzna, 790 m (GV, 3.06.2017). 
Platygyrium repens (Brid.) Schimp. - Ge 36: 49 $26^{\prime} 31,4^{\prime \prime} \mathrm{N}, 20^{\circ} 49^{\prime} 43,9^{\prime \prime} \mathrm{E}$, Wierchomla Mała, Lembarczek, kora Fagus sylvatica, buczyna, c. gem., 910 m (GV, 17.03.2019); Ge 47: 49²0'39"N, 2059'44"E, Wojkowa, kora Fraxinus excelsior obok cerkwi, 659 m (AS, 5.05.2018). Gatunek częsty w Karpatach, rzadko podawany z Beskidu Sądeckiego (MamCZARZ 1977; Stebel 2015).

! Pleurozium schreberi (Willd. ex Brid.) Mitt. - Ge 37: 49 $26^{\prime} 36^{\prime \prime} \mathrm{N}, 20^{\circ} 56^{\prime} 49^{\prime \prime} \mathrm{E}$, Krynica-Słotwiny, jedlina, 689-708 m (AS, 5.05.2018); Ge 47: 49²1'59"N, 2059'02"E, Powroźnik, obok drogi do Tylicza,

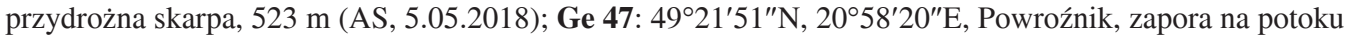
Słupne, zarośla obok zapory, 510 m (AS, 5.05.2018); Ge 47: 49²2'27"N, 2057'12"E, Powroźnik, skarpa w zaroślach obok niebieskiego szlaku turystycznego, $516 \mathrm{~m}$ (AS, 5.05.2018).

Pohlia cruda (Hedw.) Lindb. - Ge 47: 49²1'59"N, 2059'02"E, Powroźnik, obok drogi do Tylicza, gleba mineralna, przydroże, $523 \mathrm{~m}$ (AS, 5.05.2018). Mech znany z rozproszonych stanowisk w Karpatach, w Beskidzie Sądeckim bardzo rzadki (MAMCZARZ 1977; VonČINA i in. 2014).

Pohlia elongata Hedw. - Ge 25: 49³0'32,6"N, 2041'13,6"E, Rytro, przysiółek Życzanów, os. Głęboki Jar, gleba mineralna, przydroże, buczyna karpacka, c. spor., $408 \mathrm{~m}$ (GV, 17.06.2016). Rzadki w Karpatach, z Beskidu Sądeckiego znany z 2 stanowisk (MAMCZARZ 1977).

!Polytrichum commune Hedw. - Ge 37: 49 $26^{\prime} 36^{\prime \prime} \mathrm{N}, 20^{\circ} 56^{\prime} 49^{\prime \prime} \mathrm{E}$, Krynica-Słotwiny, źródliska w jedlinie, $689 \mathrm{~m}$ (AS, 5.05.2018); Ge 47: 49 $22^{\prime} 43^{\prime \prime} \mathrm{N}, 20^{\circ} 58^{\prime} 01^{\prime \prime}$, Powroźnik, skarpa w jedlinie, $588 \mathrm{~m}$ (AS, 5.05.2018).

! Pseudoscleropodium purum (Hedw.) M.Fleisch. ex Broth. - Ge 46: 49 $22^{\prime} 11^{\prime \prime} \mathrm{N}, 2^{\circ} 55^{\prime} 26^{\prime \prime} \mathrm{E}$,

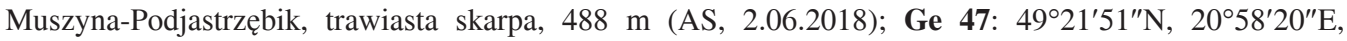
Powroźnik, zapora na potoku Słupne, zarośla obok zapory, 510 m (AS, 5.05.2018). W Karpatach znany z rozproszonych stanowisk, w Beskidzie Sądeckim rzadki (MAMCZARz 1977; STEBel 2015).

Pseudotaxiphyllum elegans (Brid.) Z.Iwats. - Ge 46: $49^{\circ} 20^{\prime} 51^{\prime \prime} \mathrm{N}, 20^{\circ} 52^{\prime} 41^{\prime \prime} \mathrm{E}$, Muszyna, rezerwat „Obrożyska”, gleba mineralna, przydroże, c. gem., 470 m (AS, 3.06.2018). Gatunek częsty w zachodniej części Beskidów (STEBEL 2006), w Beskidzie Sądeckim znany do tej pory z 3 stanowisk (MAMCZARz 1977; STEBEL 2015).

Rhynchostegium murale (Hedw.) Schimp. - Ge 23: 49³2'17,3"N, 20²4'37,6"E, Zarzecze, Skałki, zwietrzelina piaskowca, zarośla Betula pendula i Pinus sylvestris, $404 \mathrm{~m}(\mathrm{GV}, 16.03 .2019)$; Ge 25: 49 30'35,9'N, $20^{\circ} 41^{\prime} 45,0^{\prime \prime E}$, Rytro, przysiółek Życzanów, Głęboki Jar, dol. Życzanowskiego Potoku, piaskowiec, skały, c.spor., 434 m (GV, 7.06.2020). Bardzo rzadki w Beskidzie Sądeckim (MAMCZARZ 1977; STEBEL 2015).

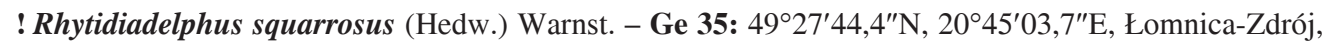
polana powyżej os. Do Potoka, gleba torfowa, młaka eutroficzna, $725 \mathrm{~m}(\mathrm{GV}, 4.06 .2017)$; Ge 46: 49²1'29"N,

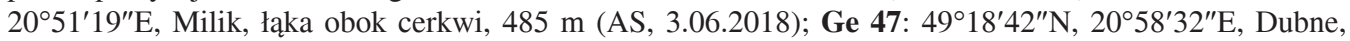
kamienny murek obok cerkwi, 625 m (AS, 3.06.2018); Ge 47: 49²1'59"N, 2059'02"E, Powroźnik, obok

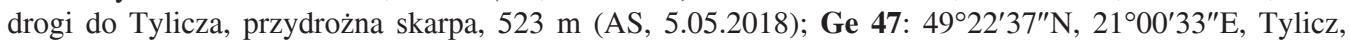
obok drogi do Powroźnika, las mieszany, $551 \mathrm{~m}$ (AS, 5.05.2018).

Rhytidium rugosum (Ehrh. ex Hedw.) Kindb. - Ge 23: 49³2'17,3"N, 20²4'37,6"E, Zarzecze, Skałki, humus na piaskowcu, zarośla Betula pendula i Pinus sylvestris, $404 \mathrm{~m}(\mathrm{GV}, 16.03 .2019)$. Mech zanikający w Karpatach, w Beskidzie Sądeckim bardzo rzadki (MAMCZARz 1977).

Rosulabryum moravicum (Podp.) Ochyra \& Stebel - Ge 23: 49³2'17,3"N, 20²4'37,6"E, Zarzecze, Skałki, zwietrzelina piaskowca, zarośla Betula pendula i Pinus sylvestris, c. gem., 404 m (GV, 16.03.2019); Ge 36: $49^{\circ} 26^{\prime} 31,4^{\prime \prime} \mathrm{N}, 20^{\circ} 49^{\prime} 43,9^{\prime \prime} \mathrm{E}$, Wierchomla Mała, Lembarczek, kora Fagus sylvatica, buczyna, $c$. gem., 910 m (GV, 17.03.2019). Bardzo częsty w Karpatach, z Beskidu Sądeckiego podawany z niewielu stanowisk (MAMCZARZ 1977).

Schistidium apocarpum (Hedw.) Bruch \& Schimp. - Ge 23: 49 $32^{\prime} 17,3^{\prime \prime} \mathrm{N}, 20^{\circ} 24^{\prime} 37,6^{\prime \prime} \mathrm{E}$, Zarzecze, Skałki, piaskowiec, zarośla Betula pendula i Pinus sylvestris, c. spor., $404 \mathrm{~m}$ (GV, 16.03.2019); Ge 25: $49^{\circ} 30^{\prime} 35,9^{\prime \prime} \mathrm{N}, 20^{\circ} 41^{\prime} 45,0^{\prime \prime} \mathrm{E}$, Rytro, przysiółek Życzanów, Głęboki Jar, dol. Życzanowskiego Potoku, piaskowiec, skały, c.spor., 419 m, $434 \mathrm{~m}$ (GV, 7.06.2020).

Schistidium crassipilum H.H.Blom - Ge 23: 49³2'17,3"N, 20²4'37,6"E, Zarzecze, Skałki, piaskowiec, zarośla Betula pendula i Pinus sylvestris, c. spor., $404 \mathrm{~m}$ (GV, 16.03.2019); Ge 25: 49³0'33,8'N, 
2041'37,0"E, Rytro, przysiółek Życzanów, Głęboki Jar, dol. Życzanowskiego Potoku, piaskowiec, skały, $419 \mathrm{~m}$ (GV, 7.06.2020). Gatunek częsty w Polsce, niedawno podany z Beskidu Sądeckiego (STEBEL 2015).

Schistidium dupretii (Thér.) W.A.Weber - Ge 47: 49 $22^{\prime} 28^{\prime \prime} \mathrm{N}, 20^{\circ} 57^{\prime} 18^{\prime \prime} \mathrm{E}$, Powroźnik, betonowy murek wśród łąk obok niebieskiego szlaku turystycznego, c. spor., $535 \mathrm{~m}$ (AS, 5.05.2018). Gatunek o słabo poznanym rozmieszczeniu w Karpatach, w Beskidzie Sądeckim znany z 1 stanowiska (STEBEL 2015).

Schistidium lancifolium (Kindb.) H.H.Blom - Ge 33: 49 $27^{\prime} 18,9^{\prime \prime} \mathrm{N}, 20^{\circ} 30^{\prime} 12,7^{\prime \prime} \mathrm{E}$, Szczawnica, Czeremcha Zachodnia, skały piaskowca, jedlina, c. spor., $779 \mathrm{~m}(\mathrm{GV}, 27.10 .2018)$ i $49^{\circ} 27^{\prime} 14,9^{\prime \prime} \mathrm{N}$, $20^{\circ} 30^{\prime} 09,7^{\prime \prime} \mathrm{E}$, c. spor., $736 \mathrm{~m}$ (GV, 27.10.2018); Ge 34: 49 $25^{\prime} 35,7^{\prime \prime} \mathrm{N}, 20^{\circ} 32^{\prime} 04,0^{\prime \prime} \mathrm{E}$, Szlachtowa, dol. Sielskiego Potoku, skały piaskowca, brzeg potoku, c. spor., $595 \mathrm{~m}$ (GV, 19.06.2016). Mech o słabo poznanym rozmieszczeniu w Karpatach, nowy dla Beskidu Sądeckiego.

Schistidium papillosum Culm. - Ge 33: 49 $27^{\prime} 28,3^{\prime \prime} \mathrm{N}, 20^{\circ} 30^{\prime} 22,9^{\prime \prime} \mathrm{E}$, Szczawnica, Czeremcha Zachodnia, skały piaskowca, jedlina, c. spor., $872 \mathrm{~m}$ i $49^{\circ} 27^{\prime} 18,9^{\prime \prime} \mathrm{N}, 20^{\circ} 30^{\prime} 12,7^{\prime \prime} \mathrm{E}$ i c. spor., $779 \mathrm{~m}$ (GV, 27.10.2018). Gatunek o słabo poznanym rozmieszczeniu w Karpatach, nowy dla Beskidu Sądeckiego.

Sciuro-hypnum plumosum (Hedw.) Ignatov \& Huttunen - Ge 25: 49 30'33, $8^{\prime \prime} \mathrm{N}, 20^{\circ} 41^{\prime} 37,0^{\prime \prime} \mathrm{E}$, Rytro, przysiółek Życzanów, Głęboki Jar, dol. Życzanowskiego Potoku, piaskowiec, skały, skarpa potoku, c.spor., 419 m (GV, 7.06.2020). Rzadki w Beskidzie Sądeckim, notowany tylko w paśmie Jaworzyny (MAMcZARZ 1977; STEBEL 2015).

(R)Serpoleskea subtilis (Hedw.) Loeske - Ge 36: 49 $24^{\prime} 13^{\prime \prime} \mathrm{N}, 20^{\circ} 51^{\prime} 30^{\prime \prime} \mathrm{E}$, Szczawnik, dol. potoku Szczawnik, kora Fagus sylvatica, c. spor., 658-680 m (AS, 2.06.2018). Mech znany z rozproszonych stanowisk w Karpatach, w Beskidzie Sądeckim rzadki (MAMCZARz 1977; STEBEL 2015).

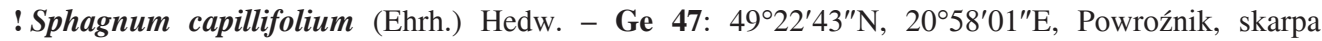
w jedlinie, 588 m (AS, 5.05.2018). W Beskidzie Sądeckim znany z rozproszonych stanowisk (MAMCZARZ 1977; STEBEL 2015).

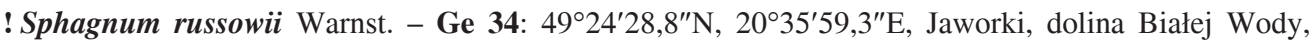
W zbocza Hrucałki, wilgotna gleba mineralna, skarpa drogi w świerczynie, 775 m (GV, 9.10.2016). Torfowiec częsty w zachodniej części Beskidów (STEBEL 2006), nie podawany do tej pory z Beskidu Sądeckiego.

! Sphagnum squarrosum Crome - Ge 36: 49 $27^{\prime} 30,1^{\prime \prime} \mathrm{N}, 20^{\circ} 49^{\prime} 28,0^{\prime \prime} \mathrm{E}$, Wierchomla Wielka, dol. potoku Potasznia, polana Młaczne, gleba torfowa, młaka eutroficzna, $740 \mathrm{~m}$ (GV, 3.06.2017). Torfowiec bardzo rzadki w Beskidzie Sądeckim (MAMCZARZ 1977).

!(R)Syntrichia papillosa (Wilson) Jur. - Ge 46: 49 $21^{\prime} 29^{\prime \prime} \mathrm{N}, 2^{\circ} 51^{\prime} 19^{\prime \prime} \mathrm{E}$, Milik, kora Tilia cordata obok cerkwi, c. gem., 485 m (AS, 3.06.2018); Ge 47: 49 $18^{\prime} 00^{\prime \prime} \mathrm{N}, 20^{\circ} 56^{\prime} 13^{\prime \prime}$ E, Leluchów, kora Tilia cordata obok cerkwi, c. gem., 524 m (AS, 3.06.2018). W Karpatach rośnie na rozproszonych stanowiskach, rzadki w Beskidzie Sądeckim (MaMCZARZ 1977; STEBEL 2015).

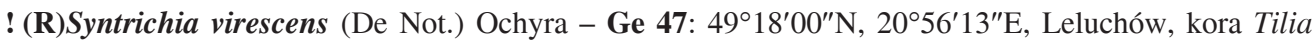

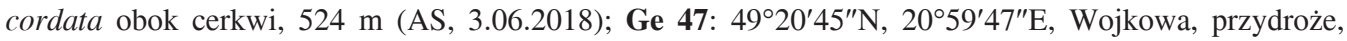
kora nasady pnia Fraxinus excelsior, 625 m (AS, 5.05.2018). W Karpatach znany z niewielu stanowisk położonych głównie w zachodniej części, w Beskidzie Sądeckim odnaleziony ostatnio na 2 stanowiskach (STEBEL 2015).

Taxiphyllum wissgrillii (Garov.) Wijk \& Margad. - Ge 25: 49 $30^{\prime} 35,9^{\prime \prime} \mathrm{N}, 20^{\circ} 41^{\prime} 45,0^{\prime \prime} \mathrm{E}$, Rytro, przysiółek Życzanów, Głęboki Jar, dol. Życzanowskiego Potoku, piaskowiec, skały, zarośla Corylus avellana, 434 m (GV, 7.06.2020). Z Beskidu Sądeckiego podany z jednego stanowiska (MAMCZARZ 1977), które budzi wątpliwości ze względu na siedlisko (gleba, murszejące drewno).

! Thamnobryum alopecurum (Hedw.) Gangulee - Ge 25: 49 $30^{\prime} 35,9^{\prime \prime} \mathrm{N}, 20^{\circ} 41^{\prime} 45,0^{\prime \prime} \mathrm{E}$, Rytro, przysiółek Życzanów, Głęboki Jar, dol. Życzanowskiego Potoku, piaskowiec, skały nad potokiem, 434 m (GV, 7.06.2020). Bardzo rzadki w Beskidzie Sądeckim (MAMCZARZ 1977).

Thamnobryum neckeroides (Hook.) E.Lawton - Ge 25: 49 30'35, $9^{\prime \prime} \mathrm{N}, 20^{\circ} 41^{\prime} 45,0^{\prime \prime} \mathrm{E}$, Rytro, przysiółek Życzanów, Głęboki Jar, dol. Życzanowskiego Potoku, piaskowiec, skały nad potokiem, $434 \mathrm{~m}$ (GV, 7.06.2020). Gatunek bardzo rzadki w Karpatach (STEBEL \& VončIna 2018), nowy dla Beskidu Sądeckiego.

! Thuidium assimile (Mitt.) A.Jaeger - Ge 35: 49 $27^{\prime} 44,4^{\prime \prime} \mathrm{N}, 20^{\circ} 45^{\prime} 03,7^{\prime \prime} \mathrm{E}$, Łomnica-Zdrój, polana powyżej os. Do Potoka, gleba torfowa, młaka eutroficzna, 725 m (GV, 4.06.2017); Ge 46: 49¹9'31"N, 
2054'19"E, Muszyna-Majdan, skarpa w zaroślach, 485 m (AS, 3.06.2018); Ge 47: 49²1'54"N, $20^{\circ} 58^{\prime} 21^{\prime \prime}$ E, Powroźnik, zapora na potoku Słupne, ocienione głazy muru zapory, $508 \mathrm{~m}$ (AS, 5.05.2018);

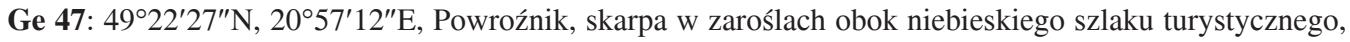
$516 \mathrm{~m}$ (AS, 5.05.2018).

! Thuidium tamariscinum (Hedw.) Schimp. - Ge 25: 49³0'38,2" N, 2041'52,5"E, Rytro, przysiółek Życzanów, Głęboki Jar, dol. Życzanowskiego Potoku, piaskowiec, skały, brzeg potoku, $454 \mathrm{~m}$ (GV, 7.06.2020); Ge 33: 49 $26^{\prime} 37,4^{\prime \prime} \mathrm{N}, 20^{\circ} 30^{\prime} 21,4^{\prime \prime} \mathrm{E}$, Szczawnica, dol. Potoku Pod Górami, próchniejące drewno jodłowe, jedlina karpacka, $611 \mathrm{~m}$ (GV, 7.05.2016); Ge 37: 49 $26^{\prime} 36^{\prime \prime} \mathrm{N}, 20^{\circ} 56^{\prime} 49^{\prime \prime} \mathrm{E}$, Krynica-Sło-

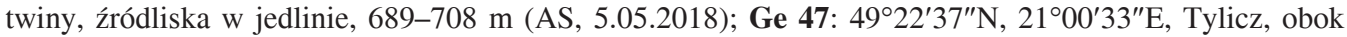
drogi do Powroźnika, las mieszany, $551 \mathrm{~m}$ (AS, 5.05.2018).

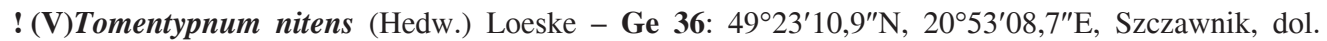
Szczawniczka, gleba torfowa, młaka eutroficzna, $578 \mathrm{~m}$ (GV, 3.06.2017). Wskutek zaniku młak mech ustępuje z flory Karpat, w Beskidzie Sądeckim bardzo rzadki (MAMCZARz 1977; SteBEL \& Vončina 2011).

Tortella inclinata (R.Hedw.) Limpr. - Ge 23: 49³2'17,3'N , 20²4'37,6"'E, Zarzecze, Skałki, glina i żwir z piaskowca, zarośla Betula pendula i Pinus sylvestris, $404 \mathrm{~m}$ (GV, 16.03.2019). Znany z rozproszonych stanowisk w Karpatach, w Beskidzie Sądeckim notowany bardzo rzadko (MAMCZARz 1977; STEBel 2015).

Tortula modica R.H.Zander - Ge 47: $49^{\circ} 18^{\prime} 42^{\prime \prime} \mathrm{N}, 2^{\circ} 58^{\prime} 32^{\prime \prime} \mathrm{E}$, Dubne, cerkiew, gleba w szczeli-

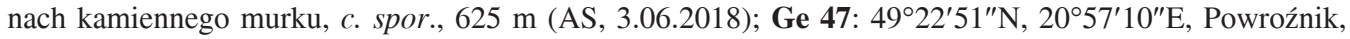
gleba mineralna, przydroże, $c$. spor., 502 m (AS, 5.05.2018). W Karpatach znany z pojedynczych stanowisk: Kotlina Żywiecka (Stebel 2008), Beskid Makowski (Stebel 2006); Pieniny (Stebel i in. 2010); Beskid Niski (WaCŁawska 1957; KarCZMarz 1987) i Pogórze Przemyskie (KarCZMarz 1975). Nowy dla Beskidu Sądeckiego (Ryc. 4).

Tortula muralis Hedw. - Ge 23: 49³2'17,3"N, 20²4'37,6"E, Zarzecze, Skałki, zwietrzelina piaskowca, zarośla Betula pendula i Pinus sylvestris, c. spor., 404 m (GV, 16.03.2019). Gatunek bardzo częsty w Karpatach, z Beskidu Sądeckiego podawany z niewielu stanowisk (MAMCZARz 1977; STEBel 2015).

Tortula subulata Hedw. - Ge 47: 49 $18^{\prime} 42^{\prime \prime} \mathrm{N}, 20^{\circ} 58^{\prime} 32^{\prime \prime} \mathrm{E}$, Dubne, kamienny murek obok cerkwi, c. spor., $625 \mathrm{~m}$ (AS, 3.06.2018). Mech znany z rozproszonych stanowisk w Karpatach (OchYRA i in. 2020) i Beskidzie Sądeckim (MAMCZARZ 1977).

Trichostomum tenuirostre (Hook. \& Taylor) Lindb. - Ge 25: 49 30'33, $8^{\prime \prime} \mathrm{N}, 20^{\circ} 41^{\prime} 37,0^{\prime \prime} \mathrm{E}$, Rytro, przysiółek Życzanów, Głęboki Jar, dol. Życzanowskiego Potoku, piaskowiec, skały, 419 m (GV, 7.06.2020). W Beskidzie Sądeckim znany z jednego stanowiska (MAMCZARZ 1977).

! (V)Ulota crispa (Hedw.) Brid. - Ge 33: 49²6'56,9"N, 20²9'22,7"E, Szczawnica, Kotelnica, kora Fagus sylvatica, buczyna karpacka, c. spor., 798 m (GV, 9.12.2018). Gatunek coraz częściej notowany w różnych regionach Karpat, w Beskidzie Sądeckim rzadki (MaMCZarz 1977; Stebel 2015).

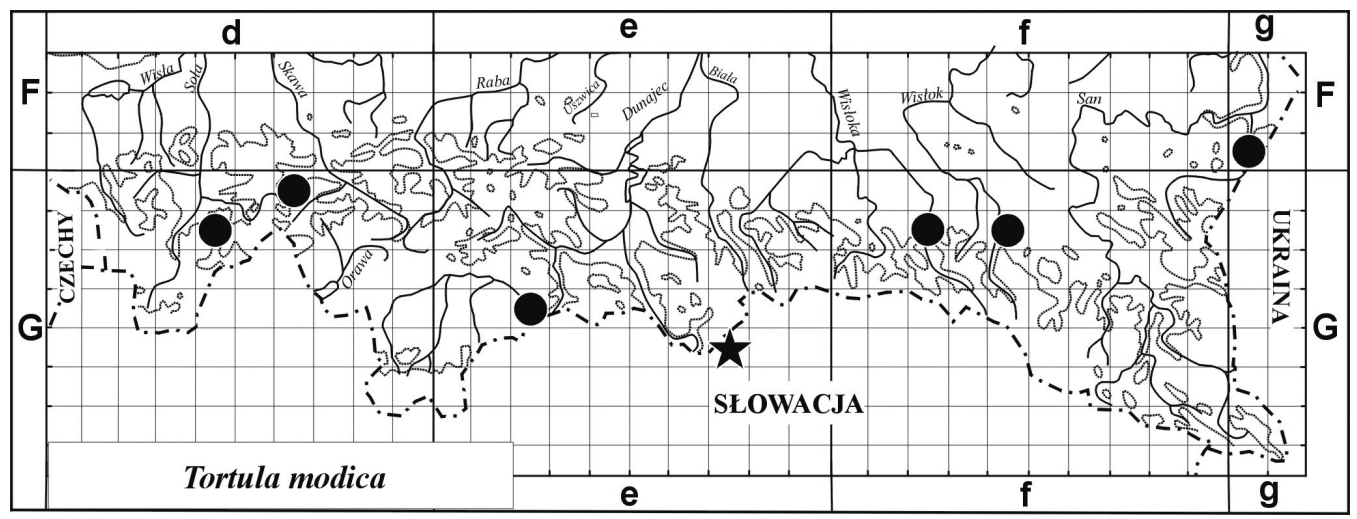

Ryc. 4. Rozmieszczenie Tortula modica w polskiej części Karpat. Gwiazdką oznaczono nowe stanowisko

Fig. 4. Distribution of Tortula modica in the Polish part of the Carpathians. Star indicates the new locality 
Weissia controversa Hedw. - Ge 46: 49 $22^{\prime} 11^{\prime \prime} \mathrm{N}, 20^{\circ} 55^{\prime} 26^{\prime \prime} \mathrm{E}$, Muszyna-Podjastrzębik, skarpa w zaroślach, c. spor., 488 m (AS, 2.06.2018). Rośnie na rozproszonych stanowiskach w Karpatach i Beskidzie Sądeckim (MAMCZARZ 1977).

!! (E)Zygodon rupestris Schimp. ex Lorentz - Ge 33: 49 27'14,9"N, 20³0'09,7"E, Szczawnica, Czeremcha Zachodnia, skały piaskowca, jedlina, c. gem., 736 m (GV, 27.10.2018). Gatunek rzadki w Karpatach, w Beskidzie Sądeckim znany z jednego stanowiska (STEBEL \& ŻARnOwIEC 2017).

\section{UWAGI KOŃCOWE}

Beskid Sądecki jest regionem o interesującej florze mchów. Jej różnorodność wynika z relatywnie niskiego przekształcenia środowiska przyrodniczego w porównaniu do większości regionów polskiej części Karpat. Stan poznania muskoflory tego pasma górskiego jest ciągle niewystarczający, o czym świadczy odkrycie w ostatnim czasie licznych gatunków nowych i rzadkich w tym regionie, publikowanych w niniejszej pracy.

Uwzględniając dane z literatury można stwierdzić, że flora mchów Beskidu Sądeckiego jest bogata i liczy 301 gatunków i 6 odmian. Z ostatnich zestawień dotyczących różnorodności gatunkowej pasm beskidzkich (OchYRA i in. 2020) wynika, że jest bogatsza np. od flor Gorców (286 gatunków i 9 odmian), masywu Babiej Góry (280 gatunków, 1 podgatunek i 7 odmian) i pasma Policy (278 gatunków i 5 odmian) w Beskidzie Wysokim. Nieznacznie więcej gatunków (304 gatunki i 3 odmiany) stwierdzono tylko w Beskidzie Śląskim. Pozostałe pasma liczą wyraźnie mniej gatunków. Wydaje się, że po rewizji okazów zielnikowych liczba mchów podanych z Beskidu Sądeckiego może ulec zmniejszeniu, ponieważ występowanie niektórych gatunków, np. Dicranum majus i Orthotrichum tenellum (MAMCZARZ 1977) budzi wątpliwości.

Podziękowania. Badania były prowadzone (A. Stebel) w ramach badań statutowych Katedry i Zakładu Botaniki Farmaceutycznej i Zielarstwa ŚUM: KNW-1-057/K/9/0.

\section{LITERATURA}

Armata L. 2005. A contribution to the bryoflora of the Pogórze Dynowskie Foothills (Western Carpathians). - Annales Universitatis Mariae Curie-Skłodowska, Sectio C Biologia 60: 101-111.

ARMATA L. 2011. Invasive tendencies of bryophytes in the flora of the Jasło-Sanok Basin (Carpathian Foothills, SE Poland). - W: A. Stebel \& R. OChyra (red.), Chorological studies on Polish Carpathians bryophytes, s. 223-232. Sorus, Poznań.

BednareK-Ochyra H. 1995. Rodzaj Racomitrium (Musci, Grimmiaceae) w Polsce: taksonomia, ekologia i fitogeografia. - Fragmenta Floristica et Geobotanica Series Polonica 2: 6-307.

Bednarek-Ochyra H., Ochyra R. \& Stebel A. 2011. The moss genus Niphotrichum (Bryophyta, Grimmiaceae) in the Polish Carpathians. - W: A. Stebel \& R. OChyra (red.), Chorological studies on Polish Carpathians bryophytes, s. 15-51. Sorus, Poznań.

BRYLSKA B. 1991. Fissidens cristatus var. mucronatus (Musci, Fissidentaceae), zapomniany takson we florze mchów Polski. - Fragmenta Floristica et Geobotanica 35(1-2): 239-244. 
ChAŁUbIŃski T. 1886. Enumeratio muscorum frondosorum Tatrensium hucusque cognitorum. s. vii +207 + Tab. 1. Drukiem Emila Skiwskiego, Warszawa.

CYkowsKa B. 2008. New records of Buxbaumia viridis (Bryophyta, Buxbaumiaceae) in the Polish Carpathians. - W: A. Stebel \& R. OchyRA (red.), Bryophytes of the Polish Carpathians, s. 251-255. Sorus, Poznań.

Fojcik B., Zubel R. \& VončIna G. 2017. 5. Eucladium verticillatum (Hedw. ex Brid.) Bruch \& Schimp. - W: P. GÓRSKI \& A. RUSIŃSKA (red.), New distributional data on bryophytes of Poland and Slovakia. 9. - Steciana 21(1): 32.

Górski P., Vončina G., Smoczyk M., Klama H., Šoltés R., Wilhelm M. \& RutKowska M. 2016. New distributional data on bryophytes of Poland and Slovakia, 8. - Steciana 20(4): 191-200.

Karczmarz K. 1975. Flora mszaków obszarów lessowych Pogórza Przemyskiego (ekologia, biologia, rozmieszczenie). - Rocznik Przemyski 15-16: 319-346.

Karczmarz K. 1979. Mszaki Pasma Bukowicy w Beskidzie Niskim. - Fragmenta Floristica et Geobotanica 25(1): 191-206.

KARCZMARZ K. 1987. Flora mszaków Beskidu Niskiego. - Annales Universitatis Mariae Curie-Skłodowska, Sectio C Biologia 42: 111-135.

Klama H. \& ŻarnowIEC J. 2011. Mszaki zespołu przyrodniczo-krajobrazowego „Gościnna Dolina” w Bielsku-Białej (Pogórze Śląskie, Południowa Polska). - Nauka Przyroda Technologie 5(4): 1-13.

Kornaś J. \& MedweCKa-Kornaś A. 1967. Zespoły roślinne Gorców. I. Naturalne i na wpół naturalne zespoły nieleśne. - Fragmenta Floristica et Geobotanica 13(2): 173-316.

KRUPA J. 1879. Stosunki florystyczne dorzecza Soły. - Sprawozdanie Komisji Fizyjograficznej Akademii Umiejętności 13: 146-182.

KRUPA J. 1882. Zapiski bryjologiczne. - Sprawozdanie Komisji Fizyjograficznej Akademii Umiejętności 16: $170-204$.

KRUPA J. 1885. Wykaz mchów zebranych w Szczawnicy w czerwcu 1884 r. - Sprawozdanie Komisji Fizyjograficznej Akademii Umiejętności 19: 165-167.

Mamczarz H. 1977. Brioflora i zbiorowiska mszaków Beskidu Sądeckiego. Część I. Brioflora Beskidu Sądeckiego. - Monographiae Botanicae 54: 1-158.

Mickiewicz J. 1969. Mchy rezerwatu „Łabowiec”. - Ochrona Przyrody 34: 67-76.

OchYRa R. 1984 [“1982”]. Mchy Skalic Nowotarskich i Spiskich (Pieniński Pas Skałkowy). - Fragmenta Floristica et Geobotanica 28(3): 419-488.

Ochyra R. \& Stebel A. 2008. Mosses of the Małe Pieniny Range (Polish Western Carpathians). - W: A. Stebel \& R. Ochyra (red.), Bryophytes of the Polish Carpathians, s. 75-141. Sorus, Poznań.

Ochyra R., Stebel A. \& BednareK-Ochyra H. 2008. The genus Hymenoloma (Bryophyta, Seligeriaceae) in the Polish Carpathians. - W: A. Stebel \& R. Ochyra (red.), Bryophytes of the Polish Carpathians, s. 211-225. Sorus, Poznań.

Ochyra R., Stebel A. \& BednareK-Ochyra H. 2011. The moss genus Paraleucobryum (Bryophyta, Dicranaceae) in the Polish Carpathians. - W: A. Stebel \& R. OchYRA (red.), Chorological Studies on Polish Carpathians Bryophytes, s. 53-98. Sorus, Poznań.

Ochyra R., Szmajda P. \& BednareK-Ochyra H. 1992. M. 600. Herzogiella striatella (Brid.) Iwats. - W: R. OChYRA \& P. SZMAJdA (red.), Atlas of the geographical distribution of mosses in Poland. Part 8, s. 51-53 + 1 mapa. W. Szafer Institute of Botany of the Polish Academy of Sciences \& Adam Mickiewicz University, Kraków - Poznań.

Ochyra R., Żarnowiec J. \& Bednarek-Ochyra H. 2003. Census catalogue of Polish mosses. s. 372. W. Szafer Institute of Botany, Polish Academy of Sciences, Kraków. 
Ochyra R., Stebel A., Klama H. \& Bieyk K. 2020. Uzupełnienia do flory mchów Pasma Policy w polskich Karpatach Zachodnich. - Fragmenta Floristica et Geobotanica Polonica 27(2): 203-252.

Ochyra R., Szmajda P., Bocheński W. \& Karczmarz K. 1988. M. 467. Cirriphyllum crassinervium (Tayl.) Fleisch. et Loeske - W: Z. ToBolEwsKI \& T. WoJTERSKI (red.), Atlas of the geographical distribution of spore plants in Poland. Series V. Mosses (Musci), Part 4, s. 45-46+ 1 mapa folio. Państwowe Wydawnictwo Naukowe, Warszawa - Poznań.

PacioreK T. 2012. New locality of moss Buxbaumia viridis (Moug. ex Lam. \& DC.) Brid. ex Moug. $\&$ Nestl. in relation to its distribution in the Beskid Sądecki range (Western Carpathians, Poland). - Časopis Slezského zemského muzea, Série A, Vědy př́rodní 61: 285-288.

PlášEK V. \& STEBel A. 2002. Bryophytes of the Čantoryjský hřbet range (Czantoria range) and its foothills (Western Carpathians - Czech Republic, Poland). - Časopis Slezského zemského muzea, Série A, Vědy př́rodní (A) 51: 1-87.

Rehman A. 1869. Zapisek botaniczny znad brzegów Popradu. - Sprawozdanie Komisji Fizyjograficznej Akademii Umiejętności 3: 56-66.

RozPORZĄDZENIE Ministra Środowiska z dnia 9 października 2014 r. w sprawie ochrony gatunkowej roślin (Dz. U. z 2014 r., poz. 1409).

StEBEL A. 1999. Nowe stanowiska rzadkich i zagrożonych mchów w Beskidach Zachodnich i na Pogórzu Zachodniobeskidzkim. - Fragmenta Floristica et Geobotanica Series Polonica 6: 203-210.

Stebel A. 2006. The mosses of the Beskidy Zachodnie as a paradigm of biological and environmental changes in the flora of the Polish Western Carpathians. Habilitation Thesis No. 17/2006. s. 347. Medical University of Silesia in Katowice, Katowice - Poznań.

Stebel A. 2008. Mosses of the Kotlina Żywiecka Basin (Western Carpathians). - W: A. Stebel \& R. OchYra (red.), Bryophytes of the Polish Carpathians, s. 11-74. Sorus, Poznań.

Stebel A. 2010. Mosses of the Beskid Mały Range (Western Carpathians). - Materiały Opracowania Centrum Dziedzictwa Przyrody Górnego Śląska 11: 1-142.

Stebel A. 2015. Contribution to the moss flora of the Poprad Landscape Park (Western Carpathians, Poland). - Nature Journal, Opole Scientific Society 48: 58-69.

Stebel A. \& Stebel A. M. 1998. Materiały do brioflory Beskidu Małego i północnej części Kotliny Żywieckiej (Karpaty Zachodnie). - Fragmenta Floristica et Geobotanica Series Polonica 5: 217-236.

Stebel A. \& VončInA G. 2011. Nowe dane do rozmieszczenia mchów zbiorowisk z klasy Scheuchzerio-Caricetea nigrae w polskiej części Karpat. - Roczniki Bieszczadzkie 19: 149-159.

Stebel A. \& VončIna G. 2017. Contribution to the bryoflora of the Ciężkowickie Foothills (Western Carpathians, Poland). - Acta Musei Silesiae Scientiae Naturales 66: 121-135.

Stebel A. \& VončIna G. 2018. The moss Thamnobryum neckeroides (Neckeraceae) in Poland. - Herzogia 31: $304-310$.

Stebel A. \& Żarnowiec J. 2017. The moss genus Zygodon (Orthotrichaceae) in Poland - distribution, ecological preferences and threats. - Cryptogamie, Bryologie 38(3): 231-251.

Stebel A., Cykowska B. \& Żarnowiec J. 2011. Current distribution of the European threatened moss Dicranum viride (Bryophyta, Dicranaceae) in the Polish Carpathians. - W: A. Stebel \& R. OchYRA (red.), Chorological studies on Polish Carpathians Bryophytes, s. 99-110. Sorus, Poznań.

Stebel A., Ochyra R. \& Vončina G. 2010. Mosses of the Pieniny Range (Polish Western Carpathians). s. 114. Sorus, Poznań.

Stebel A., Wierzcholska S. \& Vončina G. 2018. Kolejne stanowiska Dicranum viride (Dicranaceae) w Polsce. - Fragmenta Floristica et Geobotanica Polonica 25(1): 147-151. 
Stebel A., Ochyra R., Stuchlik L. \& Parusel J. 2004. Mosses of the Polica Range (Polish Western Carpathians). s. 121. Sorus, Poznań.

Stebel A., Zubel R., Fudali E., Vončina G., Wierzgoń M., Fojcik B., Staniaszek-Kik M., Wierzcholska S., Szczepański M., Piwowarski B., Smoczyk M. \& Pisarek W. 2020. Mszaki rezerwatu „Przełom Osławy pod Duszatynem”(Bieszczady Zachodnie). - Roczniki Bieszczadzkie 28: 15-40.

Vončina G. \& Stebel A. 2012. Distribution of the moss Diphyscium foliosum (Bryophyta, Diphysciaceae) in the Polish Carpathians. - Časopis Slezského zemského muzea, Série A, Vědy př́rodní 61: 237-244.

Vončina G., Wawrzczak M., Betleja L., Kozik J., KościelniaK R. \& ChachuŁa P. 2014. Bryjarka hill in Szczawnica (Beskid Sądecki Mts, Western Carpathians, Poland) - a natural and cultural focus. - Acta Musei Silesiae Scientiae Naturales 63: 111-122.

WaCŁawska Z. 1957. Mchy dorzecza górnego Wisłoku. - Fragmenta Floristica et Geobotanica 3(1): 93-113.

Żarnowiec J., Stebel A. \& Ochyra R. 2004. Threatened moss species in the Polish Carpathians in the light of a new red-list of mosses in Poland. - W: A. STEbel \& R. OchYRA (red.), Bryological studies in the Western Carpathians, s. 9-28. Sorus, Poznań.

\section{SUMMARY}

The Beskid Sądecki range is in the eastern part of the Beskidy Zachodnie Mts (Fig. 1) and covers $\sim 670 \mathrm{~km}^{2}$. The highest hill in this range is Radziejowa Mt (1266 m a.s.l.). The moss flora of the Beskid Sądecki range is well known. The first bryological information from this area was published in the second half of the 19th century (REHMAN 1869; KRUPA 1882, 1885). In 1977, a monograph of the flora of the Beskid Sacdecki bryophytes was published (MAMCZARZ 1977). Since then, many more bryological works regarding this area, with new data, have been published (BRYLSKA 1991; Ochyra et al. 1992, 2008, 2011; BEDNAREKOchyra 1995; Cykowska 2008; BednareK-Ochyra et al. 2011; Stebel \& VonČIna 2011; Stebel et al. 2011, 2018; PACioreK 2012; VonČIna \& STEBel 2012; VonČIna et al. 2014; Stebel 2015; VončIna in GóRSKI et al. 2016).

The paper presents information about 99 species and one variety of mosses, of which 36 species (e.g. Anomodon attenuatus, Neckera pennata, Zygodon rupestris) are protected and 10 (e.g. Neckera besseri, Syntrichia virescens, Tomentypnum nitens) are threatened in Poland. Eleven species (Aloina rigida, Bryum rubens, Cirriphyllum crassinervium, Eucladium verticillatum, Fissidens rufulus, Guembelia longirostris, Schistidium lancifolium, Schistidium papillosum, Sphagnum russowii, Thamnobryum neckeroides, Tortula modica) are reported for the first time from this area. The distribution of three species new to the flora of Beskid Sądecki in the Polish part of the Carpathians, namely Aloina rigida, Bryum rubens and Tortula modica, is shown in Figures 2-4.

Beskid Sądecki is a region with an interesting moss flora. Its diversity results from the relatively low transformation of the natural environment as compared to other parts of the Polish Carpathians. Knowledge of its moss flora is insufficient, as evidenced by the recent discovery of numerous new and rare species there.

Wptynęto: 25.10.2020 r.; przyjęto do druku: 29.12.2020 r. 